\title{
Do Redistributive Policies Promote Intergenerational Mobility?
}

\author{
Lutz Hendricks \\ Arizona State University
}

October 19, 1999

\begin{abstract}
Numerous public policies are aimed at improving the earnings opportunities for children of the poor and at reducing lifetime earnings inequality. This paper investigates to what extent such policies accomplish their objectives. A quantitative theory of intergenerational mobility and lifetime earnings inequality is developed and parameterized to match selected features of U.S. data. Numerical experiments are used to measure the steady state effects of policies that increase the returns to human capital accumulation for children of the poor, either by lowering the private costs of education or by reducing labor income taxes for the poor. The main finding is that such policies have very little impact on intergenerational earnings mobility. Moreover, policies that reduce the private costs of education fail to reduce lifetime earnings inequality. These findings suggest that redistributive tax and subsidy policies of the kind studied here may be largely ineffective in promoting equality of opportunity.
\end{abstract}

JEL: D3, H2, J24. Keywords: Taxation; intergenerational mobility; human capital.

Correspondence address: Arizona State University, Department of Economics, PO Box 873806. Tempe, AZ 85287-3806. hendricks.lutz@ asu.edu. http://www.public.asu.edu/ hendrick.

Phone: (480) 965-1462. 


\section{Introduction}

This paper investigates how redistributive policies affect intergenerational earnings mobility and lifetime earnings inequality. Numerous public policies are aimed at promoting "equality of opportunity" in the sense of improving the earnings opportunities for children of the poor. Examples include public education finance, tax exemptions on savings earmarked for educational purposes, and subsidized student loans. Promoting intergenerational mobility is also a secondary objective of redistributive tax-transfer policies, whose primary objective is to reduce earnings inequality. This paper investigates to what extent such policies accomplish their objectives. Specifically, the paper seeks to answer two questions: (i) Do policies that raise the returns to human capital accumulation promote intergenerational earnings mobility? (ii) Do such policies reduce lifetime earnings inequality?

Answering these questions requires a quantitative theory of intergenerational earnings mobility and lifetime earnings inequality that is consistent with key features of the data. Since little is known about how intergenerational mobility varies with parental characteristics, such as schooling and ability, the paper constructs a dataset of matched parents and children and develops a set of stylized intergenerational mobility facts. It then offers a model that can quantitatively account for these stylized facts. The model combines the features of a conventional life-cycle model with a theory of the intergenerational transmission of education and ability along the lines of Becker and Tomes (1986, hereafter BT). The model is calibrated to U.S. data and numerical simulations are used to measure the steady state effects of redistributive policies.

The paper first studies policies that reduce the private costs of education. The particular policy experiment examined is a tuition subsidy, but it is intended to capture the effects of other policies that distort the same relative price, such as subsidized student loans or tax-exemptions of savings earmarked for education. The main finding is that such policies have minimal impact on intergenerational earnings mobility. This holds despite the fact that education subsidies can have large effects on educational investment. Tuition subsidies also fail to reduce lifetime earnings inequality. In fact, some measures of inequality, such as the quintile ratio, actually increase with the tuition subsidy. The reason is that low ability agents are induced to invest in education, even though this reduces their lifetime earnings.

The paper next examines whether redistributive tax policies are more successful in promoting intergenerational mobility. The specific policy experiment studied is the move from flat rate to progressive labor income taxes modeled after the U.S. tax system. This experiment is designed 
to capture policies that increase the relative reward of investing in education for lower ability agents. The induced changes in intergenerational mobility are again minimal. However, the progressive tax reduces lifetime earnings inequality as measured by the quintile ratio by $10 \%$.

These findings suggest that redistributive tax and subsidy policies of the kind studied here may be largely ineffective for promoting "equality of opportunity." The intuition for this result is as follows. Individual earnings are determined by an unmeasured ability endowment and by human capital investments. Intergenerational persistence arises as parental ability and human capital affect the distribution of child abilities. Public policy can therefore affect intergenerational persistence by changing parental education and job training investments. However, the policies studied here have little effect on job training for reasons that are wellknown, mainly because job training inputs are paid for by foregone earnings. The policies do have a substantial impact on parental education. However, viewing the data through the lens of the model reveals that parental education has a limited impact on child abilities, once parental abilities are controlled for. Since the distribution of earnings is determined largely by abilities, very large changes in parental education choices are required to significantly alter child earnings. This logic suggests that policies which affect only education but not other human capital investments are not effective tools for changing intergenerational earnings mobility.

The finding that redistributive policies have little effect on intergenerational mobility thus depends on the empirical observation that parental education has a limited impact on child ability once parental ability is controlled for. It is important to emphasize that this observation is not independent of theory. It requires identifying assumptions provided by the model. An important task for future research is therefore to investigate the robustness of the findings under alternative models of the transmission of ability and education.

This paper contributes to two strands of the literature. First, it contributes to the emerging literature studying the effects of public policies on intergenerational mobility. Knowles (1999) investigates the impact of redistributive tax policies on the welfare of the poor in a model with realistic intergenerational mobility properties. In his model intergenerational persistence is due to two features that are most relevant for low income parents: fertility choice and borrowing constraints. Since these features are abstracted from in the present paper, his work should be viewed as complementary to mine. The paper also contributes to the literature studying the effects of tax policies on inequality. Most existing studies have abstracted from human capital accumulation and find very small changes in earnings inequality (e.g., Castaneda et al. 1998). Notable exceptions are Heckman et al. (1998, hereafter HLT) and Knowles (1999). This paper extends HLT's work mainly by allowing for intergenerational transmission of education and ability. 
The rest of this paper is organized as follows. Section 2 summarizes the intergenerational mobility observations that motivate the model developed in section 3 . The choice of model parameters is given in section 4 , followed by simulation results in section 5 . The final section concludes.

\section{Intergenerational Mobility Facts}

This section provides estimates of the intergenerational persistence of earnings and education for a sample of U.S. workers. A number of stylized facts are documented that provide the basis for the model presented in section 3. Only an outline of the empirical approach is presented here together with the main findings. Details are provided in the data appendix of Hendricks (1999c).

\subsection{Empirical Approach}

The data are taken from the 1968 to 1992 waves of the Panel Study of Income Dynamics (PSID). For an individual to be included, he/she has to satisfy the following criteria: At least 10 years with positive earnings must be observed at ages between 18 and 70 while the individual is "head" or "wife" of the household. Education must be reported in at least one year after the age of 30 (to make sure that reported education does not change at some later age). Annual work hours must lie between 500 and 4000. The individual must have positive sample weight. Estimating intergenerational mobility from observations that combine men and women is difficult because it is not clear whether the gender earnings gap reflects differences in human capital, the disruption of female work histories during child-rearing, or discrimination. All results presented here are therefore obtained from all-male samples. ${ }^{1}$

It is assumed that individual earnings are determined by unmeasured ability, education, age, sex, and a transitory idiosyncratic shock. Abilities are divided into $q=1, \ldots, n_{q}$ classes with equal mass in each $\left(\operatorname{Pr}(q)=1 / n_{q}\right) .^{2}$ The choice of $n_{q}$ is determined by two opposing considerations. On the one hand, a larger $n_{q}$ yields a more precise description of the earnings distribution. On the other hand, it reduces the number of observations in each ability/education cell and makes the results harder to understand. The results reported here are therefore based

\footnotetext{
${ }^{1}$ Allowing for daughters in addition to sons changes the findings little. However, mothers are found to affect the earnings and education of their offspring much less than fathers.

${ }^{2}$ Throughout the paper, the notation $\operatorname{Pr}(q, s)$ is used to denote the joint distribution of $q$ and $s . \operatorname{Pr}(q)$ denotes the marginal distribution, and $\operatorname{Pr}(q \mid s)$ is the conditional distribution.
} 
on $n_{q}=4$, but increasing $n_{q}$ up to 7 makes little difference. Educational attainment is divided into $n_{s}=2$ classes, where $s=1$ represents up to 15 years of schooling and $s=2$ represents more than 15 years of schooling. I refer to the each group by the highest degree attained by the typical group member (high school graduates and college graduates, respectively).

The first step characterizes the distribution of lifetime earnings in each education/sex group. This is accomplished by estimating earnings regressions of the form

$$
\ln \left(y_{a, i}\right)=\chi_{i}+\beta_{1} a+\beta_{2} a^{2}+\xi_{a, i}
$$

separately for each group. Here $y$ denotes annual earnings in 1992 dollars, $i$ indexes the individual, $a$ is age, and $\xi$ is an i.i.d. disturbance. ${ }^{3}$ Denote by $\hat{\chi}_{i}$ the intercept $\chi_{i}$ purged of cohort effects using a linear regression of the $\chi_{i}$ on birth years. Each individual is assigned a present value of earnings proportional to $e^{\hat{\chi}_{i}}$ :

$$
E_{i}=\sum_{a=a_{s}+1}^{a_{R}} \exp \left(\hat{\chi}_{i}+\beta_{1} a+\beta_{2} a^{2}\right) / D_{a}
$$

where $D_{a}=1.035^{a-16}$ is cumulative discount factor based on an interest rate of $3.5 \%$, which is close to the one generated by the model below. Note that the age at which earnings begin differs by schooling class, but earnings are discounted to a common age of 16 for all individuals. This is important for capturing the main cost of attending college, foregone earnings.

The result is a joint distribution of the present values of earnings and schooling in each group. An algorithm described in Hendricks (1999c) is then used to assign households to ability classes, which allows to estimate the mean present values of earnings in each $(q, s)$ class, $E_{q, s}$ together with the population share of each class $\operatorname{Pr}(q, s)$. The algorithm requires the identifying assumption is that earnings increase with ability within each schooling class.

The second step matches parents with their children and constructs intergenerational transition probabilities, $\operatorname{Pr}\left(q \mid q^{P}, s^{P}\right)$ and $\operatorname{Pr}\left(s \mid q, s^{P}\right)$, where the superscript $P$ indicates parental variables. For example, the distribution of child abilities conditional on parental abilities and education, $\operatorname{Pr}\left(q \mid q^{P}, s^{P}\right)$ is estimated as the fraction of children of ability $q$ of all children whose parents have ability $q^{P}$ and schooling $s^{P}$. Since the characteristics of parents and children are not identical, the estimated transition probabilities are not consistent with the model's requirement that the distribution of $(q, s)$ be stationary. The transition probabilities are therefore adjusted

\footnotetext{
${ }^{3}$ In a more general ARMA model, Moffitt and Gottschalk (1993) show that the serial correlation of transitory component of earnings is very small.
} 
such that they generate the observed distribution $\operatorname{Pr}(q, s)$ as the stationary distribution (see Hendricks 1999c for details).

Clearly, this estimation approach could be extended in various ways. A number of authors suggest to use instrumental variables in the estimation of lifetime earnings. Given that the sample includes at least 10 years of observations for each individual (and in many cases more than 20 years), it seems preferable not to do so. Additional explanatory variables could be included in the regression equation. For example, one might attempt to control for the increase in the college premium by allowing the return to education to vary over time. Alternative approaches for estimating transition matrices could be imagined. Instead of pursuing these extensions, I provide a model sensitivity analysis below which suggests that the findings are robust to sensible variations in intergenerational persistence measures.

\subsection{Empirical Findings}

Average lifetime earnings by ability and education $\left(E_{q, s}\right)$, measured in 1992 dollars, are shown in table 1. Two important insights emerge. First, variation in ability determines most of the variation in earnings. The top quartile earns about 4 times more than the bottom quartile, whereas a college education increases earnings by at most $16 \%$. This is consistent with the common finding that education and other observable characteristics account for only a fraction of lifetime earnings variation (e.g., Fullerton and Rogers 1993). The second finding is that obtaining a college degree increases the present value of earnings substantially only for the highest $q$ class. This finding appears surprising at first, but is supported by HLT based on different data and estimation procedures. Attaining college increases peak earnings for all $q$, but the present value of earnings increases by less than peak earnings because college attendance postpones the start of work life by four years. An important implication is that lower taxes may lead low ability households to reduce college attendance.

\section{[INSERT TABLE 1 HERE]}

Transition probabilities for schooling are shown in table 2. The main observation is that, even controlling for the child's ability, parental schooling substantially increases the probability that the child attains college. This strongly suggests that schooling is transmitted to the child independently of ability.

\section{[INSERT TABLE 2 HERE]}

Transition probabilities for abilities, shown in table 3, exhibit considerable persistence. For example, for a parent with college degree the probability of having a child in the top ability class is $42 \%$ for $q^{P}=4$ compared with $19.9 \%$ for $q^{P}=1$. However, it is not only the parent's 
ability that determines the child's ability, parental schooling also has a significant effect. These findings motivate how the intergenerational transmission of earnings is modeled below.

\section{[INSERT TABLE 3 HERE]}

\section{The Model}

The model combines a conventional life-cycle model along the lines of HLT with a theory of the intergenerational transmission of human capital along the lines of Becker and Tomes (1986). There are three types of agents: households, firms, and a government. Only steady states are considered.

\subsection{Households}

At each date a cohort of unit measure is born which lives for $a_{L}$ periods. The household is inactive until age $a_{0}$, engages in full-time schooling until age $a_{S}$, works until age $a_{R}$ and is retired thereafter. Each household gives birth to a single child at age $a_{B}$.

Households are endowed with an ability parameter $q \in\left\{1,2, \ldots, n_{q}\right\}$ and schooling cost parameters for each education level, $p_{s}, s \in\left\{1, \ldots, n_{s}\right\}$. These represent non-pecuniary costs of schooling and are drawn independently across households from a continuous distribution. Each household chooses the schooling level, $s$, and an age profile of job training investments so as to maximize the present value of lifetime earnings net of education costs. The household then chooses a lifetime profile of consumption subject to a present value budget constraint. Household variables are therefore indexed by birth date, age, ability and education. For example, consumption at a particular age would be denoted $c_{b, a}^{q, s}$. However, in what follows I suppress the $(q, s)$ superscripts where there is no risk of confusion.

It is convenient to solve the household problem in two parts: First, the household chooses education and training so as to maximize the present value of earnings. Then it chooses consumption subject to a present value budget constraint.

\subsubsection{Earnings Maximization}

At the beginning of active life, at age $a_{0}$, the household is endowed with an ability level $q$ and draws schooling cost parameters $p_{s}$ from a distribution described below. Next, the household chooses between $n_{s}$ discrete schooling levels corresponding to different values of $a_{s}$, $p_{s}$, and flow tuition costs $d_{s}$. As a result of choosing education level $s$ a worker with ability $q$ begins work life with a human capital endowment of $H_{q, s}$. Then, at ages $a_{s}+1$ through $a_{R}$, the 
household chooses job training investments in the form of time $(v)$ and purchased goods $(x)$. The objective is to maximize the present value of earnings net of taxes and education costs

$$
\max _{s, x_{b, a}, v_{b, a}} E_{q, s}-p_{s}
$$

where the present value of earnings is given by

$$
E_{q, s}=\sum_{a=a_{S}+1}^{a_{R}} y_{b, a}^{q, s} / D_{b, a}-\sum_{a=a_{0}}^{a_{S}} d_{s} / D_{b, a}
$$

and the flow of earnings is $y_{b, a}^{q, s}=\omega_{b+a-1}^{S}\left(1-v_{b, a}\right) h_{b, a}-x_{b, a}-T_{w}(b, a)$.

Here, $\omega_{b+a-1}^{s}$ is the pre-tax wage rate per efficiency unit of labor of type $s$ at date $b+a-1$ (when the household born at $b$ is age $a$ ). The household earns $\omega h$, but spends $\omega v h$ on training time and $x$ on training goods. In addition, the amount $T_{w}$ is spent on labor income taxes. The labor tax function depends on pre-tax earnings and is assumed to be differentiable. Slightly abusing notation, I write $T_{w}(b, a)=T_{w}\left(\omega_{b+a-1}^{s}\left(1-v_{b, a}\right) h_{b, a}-x_{b, a}\right)$. The cumulative discount factors are

$$
D_{b, a}=\prod_{\hat{a}=a_{0}}^{a} R_{b+\hat{a}-1},
$$

where $R$ is the gross rate of return on capital after taxes. Note that $E$ is computed from pre-tax prices because total tax payments cannot be computed from marginal tax rates. However, the discount factor uses the after-tax interest rate. During work life human capital evolves according to

$$
h_{b, a+1}=\left(1-\delta_{h}\right) h_{b, a}+G\left(h_{b, a}, x_{b, a}, v_{b, a}, s\right)
$$

with initial condition $h_{b, a_{S}+1}=H_{q, s}$. Here, $\delta_{h}$ is the depreciation rate of human capital and $G$ is the production function for job training which varies by education level.

\subsubsection{Consumption Choice}

Given optimal levels of schooling and job-training, the household chooses a consumption path that maximizes the discounted sum of utilities

$$
\max \sum_{a=a_{C}}^{a_{L}} \beta^{a} u\left(c_{b, a}\right)
$$

where $\beta>0$ is a discount factor. Consumption begins at age $a_{C}$. The household starts with asset holdings of $k_{b, a_{0}}=0$. The flow budget constraint is 


$$
k_{b, a+1}=k_{b, a} R_{b+a-1}+y_{b, a}^{q, s}-c_{b, a}-d_{b, a}^{s}+z_{b, a}
$$

with terminal condition $k_{b, a_{L}+1}=0 . z$ is a lump-sum transfer. Optimal consumption is governed by a standard Euler equation.

$$
u^{\prime}\left(c_{b, a}\right)=\beta R_{b+a} u^{\prime}\left(c_{b, a+1}\right)
$$

A solution of the household problem consists of age profiles for $\{c, k, h, x, v\}$ and a scalar $s$ that satisfy $(i)$ the conditions for optimal job training; (ii) the consumption Euler equation (2) and (iii) the budget constraint (1); (iv) the law of motion for $h$; $(v)$ the choice of $s$ maximizes the present value of earnings.

\subsection{Intergenerational Transmission of Ability}

Up to this point the specification of the household sector has been conventional (see especially HLT). The novel feature is the modeling of the intergenerational transmission of human capital. The main difficulty here is the paucity of data measuring parental (or other) inputs in children's human capital accumulation. As a consequence, even the nature of the transmission mechanism is uncertain. Human capital may be transmitted through genetic (or otherwise exogenous) inheritance, via parental investment, or through peer spillovers, such as learning by watching. The literature has mainly pursued the first two of these channels. ${ }^{4}$

The first approach was pioneered by BT who posit a Galton-style regression to the mean equation for the intergenerational transmission of abilities $(Q)$ of the form

$$
\ln (Q)=\bar{q}+\alpha \ln \left(Q^{P}\right)+\varepsilon
$$

where the superscript $P$ indicates parental variables, $\bar{q}$ and $\alpha$ are parameters, and $\varepsilon$ is an i.i.d. disturbance. This setup may be labeled "pure nature" because it most appropriately describes a genetic transfer of abilities, which is independent of parental behavior. In this model intergenerational persistence has two sources: the exogenous inheritance of ability and the dependence of human capital investment on parental characteristics. As shown by BT, for parents who are not borrowing constrained only the first channel generates persistence as unconstrained parents choose the level of human capital investment that maximizes child earnings, regardless of parental characteristics.

\footnotetext{
${ }^{4}$ The peer spillover approach plays a role in models of local education finance such as Fernandez and Rogerson (1997).
} 
The benefit of this approach is that it can be quantified without measuring parental investment in child ability. Since the transfer of ability is exogenous, it is admissible to estimate a reduced form equation of the form (3) and impose it as a primitive on the model. However, the approach needs to be extended in order to be consistent with a number of empirical observations, especially with the notion that parental behavior affects child outcomes. ${ }^{5}$ In the data presented above this is reflected in the fact that parental education choice affects child outcomes, even after controlling for parental and child ability.

The literature has addressed this issue in two ways. A number of authors have suggested alternatives to BT's framework in which child human capital is solely determined by parental investment. Intergenerational persistence is then generated by assumptions about the human capital production technology or about parental preferences which guarantee that richer parents invest more in their children (e.g., Ehrlich and Lui 1990). However, given the paucity of data, such models are difficult to quantify (see the discussion in Aiyagari et al. 2000). Recent quantitative studies have therefore returned to versions of BT's original framework. Restuccia and Urrutia (1999) posit a special case of BT in which ability is uncorrelated across cohorts. Intergenerational persistence is then entirely due to borrowing constraints. A similar approach is pursued by Knowles (1999), but in his model intergenerational persistence also arises because poor parents have more children and invest less in their human capital. A key difficulty with both models is that they generate too little persistence for high income (or high wealth) parents who invest the earnings maximizing amount in child human capital.

The present model is also based on BT, but extends it in different directions as suggested by the empirical findings of section 2. In particular, it is important to capture the notion that parental behavior affects child outcomes. In my data, parental education affects child ability, controlling for parental ability. This is captured by assuming that parental human capital (both endowed and acquired) stochastically determines child ability. In addition, parental education affects child education, controlling for parental and child ability. This observation is captured by assuming that the schooling cost $p_{s}$ is stochastically transmitted from parents to children.

Formally, I assume that the ability parameter of a child with a parent who has human capital $h^{P}$ at the time the child is born is governed by a Galton equation analogous to (3),

$$
\ln (\hat{Q})=\bar{q}+\alpha\left(s^{P}\right) \ln \left(h^{P}\right)+\varepsilon
$$

\footnotetext{
${ }^{5}$ It seems uncontroversial that both nature and nurture affect child outcomes, even if some evidence suggests that a substantial fraction of intergenerational persistence may be genetic; see Behrman and Taubman (1989).
} 
where $\varepsilon$ is an i.i.d. disturbance term with distribution $\mathrm{N}\left(0, \sigma_{\varepsilon}\right)$ and $\bar{q}$ may be normalized to zero. Parental abilities and schooling determine $h^{P}$ and are therefore transmitted to the children. Permitting the transmission parameter $\alpha$ to depend on parental schooling as well allows the model to replicate the empirical transition probabilities slightly better, but is not important for the quantitative results (in the calibrated model $\alpha(1)$ and $\alpha\left(n_{s}\right)$ differ by less than $7 \%$ ).

For computational purposes, the continuously distributed $\hat{Q}$ is rounded to a finite grid of ability levels, $Q_{q}, q=1, \ldots, n_{q}$. In particular, the child's $q$ is given by the lowest grid point below $\hat{Q}: \quad q=\max \left\{\hat{q} \mid Q_{\hat{q}} \leq \hat{Q}\right\}$. For a given parent, the probability that the child has $\ln (\hat{Q})<\ln \left(Q_{q}\right)$ is

$$
\Theta\left(q \mid q^{P}, s^{P}\right)=\operatorname{Pr}\left\{\varepsilon<\ln \left(Q_{q}\right)-\alpha\left(s^{P}\right) \ln \left(h^{P}\right)\right\}=\Phi\left(\ln \left(Q_{q}\right)-\alpha\left(s^{P}\right) \ln \left(h^{P}\right)\right)
$$

where $\Phi$ is the normal cdf with standard deviation $\sigma_{\varepsilon}$. Define $\Theta(0 \mid .,)=$.0 . The transition probabilities are then

$$
\operatorname{Pr}\left(q \mid q^{P}, s^{P}\right)=\Theta\left(q \mid q^{P}, s^{P}\right)-\Theta\left(q-1 \mid q^{P}, s^{P}\right)
$$

One benefit of this specification is to remain close to the structure introduced by BT, which is arguably the leading theory of intergenerational mobility, while at the same time being consistent with the stylized facts pointed out in section 2 . The model abstracts from a number of features that have been suggested in the literature. Allowing for parental investment in child human capital would not change any results as long as parents invest the earnings maximizing amount (see BT). Borrowing constraints could invalidate this result, but Cameron and Heckman (1998) suggest that these are not empirically important. Allowing for parental fertility choice, as suggested by Knowles (1999), might be important, especially for the poorest households. Clearly, alternative models could be equally consistent with the data and should be explored in future research.

The present model may be thought of as the "pure nurture" counterpart to BT's "pure nature" model in that all skill components (ability, education, training) are affected by individual behavior. There is no room for genetically transmitted (or otherwise exogenous) endowments. In the data, it is likely that both genetic ("nature") and acquired ("nurture") abilities are transmitted, although their relative importance is controversial. A possible concern is therefore that a pure nurture model may overstate the responsiveness of intergenerational mobility to policy changes. However, this only strengthens the main finding that the policies studied here have very little effect on intergenerational persistence. 


\subsection{Firms}

Firms produce output according to the constant returns to scale production function $Y_{t}=F\left(K_{t}, L_{t}^{1}, \ldots, L_{t}^{n_{S}}\right)$, where $K$ is capital input and $L^{s}$ denotes labor input of schooling level $s$. Firms rent all inputs from households and maximize period profits. The first order conditions are standard: $r_{t}=F_{K}(t), \omega_{t}^{s}=F_{L^{S}}(t)$.

\subsection{Government}

The government imposes capital and labor income taxes on households. Each household receives a lump-sum transfer equal to its own tax payments. The government therefore collects zero net revenues from each individual, which ensures that the tax reform has no direct redistributional effects. A more conventional specification would redistribute tax revenues in equal lump-sum payments to all households. This would make it harder to interpret the results because it distributes wealth across old and young cohorts, which distorts savings decisions. The capital tax rate is exogenous, $\tau_{K}$. The labor tax rate is determined by the tax function $T_{w}$ which is piecewise linear in earnings.

\subsection{Equilibrium}

There are $n_{q} \cdot n_{s}$ household classes. Within each class, all households behave identically. Let $\operatorname{Pr}_{b}(q, s)$ be the mass of households with ability $q$ and schooling $s$ in cohort $b$. A competitive equilibrium consists of a sequence of prices $\left(r_{t}, \omega_{t}^{s}, R_{t}\right)$, a sequence of aggregate quantities $\left(Y_{t}, K_{t}, L_{t}^{s}\right)$, a distribution of household types $\operatorname{Pr}_{b}(q, s)$, transition matrices $\operatorname{Pr}_{b}\left(q, s \mid q^{P}, s^{P}\right)$, and a sequence of household age profiles $\left(c_{b, a}^{q, s}, x_{b, a}^{q, s}, v_{b, a}^{q, s}, h_{b, a}^{q, s}, k_{b, a}^{q, s}, d_{b, a}^{q, s}, z_{b, a}^{q, s}, \lambda_{b, a}^{q, s}, E_{b}^{q, s}\right)$.

These satisfy the following conditions. (i) Factor prices $\left(r_{t}, \omega_{t}^{s}\right)$ are consistent with the firm's first-order condition. (ii) The after tax rate of return is $R_{t}=1+\left(1-\tau_{K, t}\right)\left(r_{t}-\delta_{k}\right)$. (iii) Household age profiles solve the household problem, where transfers rebate all tax payments:

$$
z_{b, a}^{q, s}=T_{w}\left(\omega_{b+a-1}^{s}\left(1-v_{b, a}^{q, s}\right) h_{b, a}^{q, s}-x_{b, a}^{q, s}\right)+\tau_{K, b+a-1}\left(r_{b+a-1}-\delta_{k}\right) k_{b, a}^{q, s} .
$$

(iv) The distribution of types is consistent with the household's optimal education choice of $\operatorname{Pr}_{b}\left(s \mid q, s^{P}\right)$ and with (5). (v) Goods markets clear: $Y_{t}=C_{t}+X_{t}+K_{t+1}-\left(1-\delta_{k}\right) K_{t}$, where $C_{t}$ denotes aggregate consumption and $X_{t}$ is aggregate job-training investment. (vi) Factor markets clear:

$$
L_{t}^{s}=\sum_{q} \sum_{a=a_{S}+1}^{a_{R}} \operatorname{Pr}_{t-a+1}(q, s)\left(1-v_{t-a+1, a}^{q, s}\right) h_{t-a+1, a}^{q, s}
$$




$$
K_{t}=\sum_{q, s} \sum_{a=a_{0}}^{a_{L}} \operatorname{Pr}_{t-a+1}(q, s) k_{t-a+1, a}^{q, s}
$$

In what follows, the analysis is restricted to steady states, in which all variables are constant over time.

\section{Parameter Choices}

The model parameters, summarized in table 4, are chosen based on aggregate U.S. observations and on the intergenerational mobility facts documented in section 2. More detail is provided in the appendix.

[INSERT TABLE 4 HERE]

\subsection{Households}

Agents die at age $a_{L}=75$ and retire at age $a_{R}=64$. Schooling begins at age $a_{0}=7$ (based on enrollment data in Cohn and Geske 1990, table 1.2). Children are born when parents are aged $a_{B}=30$. Consumption begins at age $a_{C}=16$. The utility function is assumed to be of the form $u(c)=c^{1-\sigma} /(1-\sigma)$ with a conventional value of $\sigma=2 . \beta$ is chosen to match a capital-output ratio of 2.5 .

Schooling. The parameters to be chosen for each schooling level are: $a_{s}, d^{s}, H_{q, s}$, and the parameters that govern the distribution of schooling costs. There are $n_{s}=2$ schooling levels corresponding to high school completion $\left(a_{S}=a_{0}+11\right)$ and college graduation $\left(a_{s}=a_{0}+15\right)$. The amounts of human capital produced by each schooling level, $H_{q, s}$, are chosen to replicate observed relative earnings levels $\left(E_{q, s}\right)$. If labor of different types are perfect substitutes, then $H_{1,1}$ is normalized to one, while the other $H_{1, s}$ are then chosen to replicate earnings relative to $E_{1,1}$. Otherwise, $H_{1, s}$ is normalized to 1 for all $s$ and the relative earnings of various $s$ types are governed by parameters of the production function.

The schooling cost parameter $p_{s}$ is normalized to zero for the lowest schooling level and drawn from a normal distribution with mean $\mu\left(q, s^{P}\right)$ and standard deviation $\sigma(q)$ for $s=2$. The dependence of $\mu$ on parental schooling creates intergenerational persistence in schooling. For parsimony, mean college costs are assumed to be of the form $\mu\left(q, s^{P}\right)=\mu(q)+a b s(\mu(q)) \cdot v\left(s^{P}\right)$. The $\mu(q)$ are chosen to replicate the fraction of college graduates in each earnings class in the data, $\operatorname{Pr}(s \mid q)$. I normalize $v(1)=0$ and choose $v(2)<0$ to replicate the difference in college attendance between children of parents who are college graduates as opposed to high school graduates, $P\left(s=2 \mid s^{P}=2\right)-P\left(s=2 \mid s^{P}=1\right)$. The standard deviation of $p_{\mathrm{s}}$ is to match estimates of the responsiveness of college enrollment to 
tuition changes (Kane 1994). Based on Cohn and Geske (1990) the tuition cost of college is set to $0.5 \%$ of aggregate output.

Job Training. As is conventional in this literature, the production function for human capital is assumed to be of the form $G=B_{s} h_{q, s}(v h)^{\varphi} x^{\psi}$. The parameters to be chosen are then $B_{s}$, $\varphi, \psi$, and $\delta_{h}$. Following HLT $\delta_{h}$ is set to 0 . There is a range of parameter estimates in the literature for $\varphi$ and $\psi$. An intermediate value for returns to scale is $\varphi+\psi=0.75$. At least half of the total cost of job training is due to time inputs, which suggests $\varphi=0.45$ and $\psi=0.3$. Learning productivity is chosen so as to replicate earnings growth between the ages of 25 and 48 as implied by the estimated earnings equations described above.

Intergenerational Mobility. The grid points $\left(Q_{q}\right)$ are chosen to match the desired $\operatorname{Pr}(q)$. The transmission coefficients in the Galton equation $\left[\alpha\left(s^{P}\right)\right]$ are chosen to replicate the stationary transition probability that high ability parents have high ability children, $\operatorname{Pr}\left(q>2 \mid q^{P}>2, s^{P}\right)$. The variance of $\varepsilon$ is normalized to one. This is possible because changing $\sigma_{\varepsilon}, \alpha\left(s^{P}\right)$, and $\ln \left(Q_{q}\right)$ by a common factor leaves the equilibrium unchanged.

\subsection{Firms}

The production function is of the form $F=K^{\theta} L^{1-\theta}$ where $L$ is a labor aggregator. The parameter $\theta$ is set to 0.3 so as to match the U.S. capital income share. The depreciation rate $\delta_{K}$ is chosen to replicate a capital output ratio of 2.5 and an investment share in GDP of $I / Y=0.2$. In steady state $K=\left(1-\delta_{K}\right) K+I$. Therefore, $\delta_{K}=\left(I_{K} / Y\right)(Y / K)=0.08$. In the baseline case, $L$ is a CES aggregator of labor of different schooling levels:

$$
L=\left(v_{1}\left(L^{1}\right)^{\rho}+v_{2}\left(L^{2}\right)^{\rho}\right)^{1 / \rho}
$$

with $v_{1}+v_{2}=1$. The elasticity of substitution between high school and college labor is taken from HLT: $1 /(1-\rho)=1.441$. The weights $v_{s}$ are set to match the average ratio of college to high school present value of earnings. I also explore the case where the different types of labor are perfect substitutes: $L=L^{1}+L^{2}$. The parameters $v_{s}$ and $\rho$ are then dropped.

\subsection{Tax Rates}

Following HLT, the capital tax rate is set to 0.15 . Define net earnings as $\hat{y}=y-y^{*}$ where $y^{*}$ is a deductible. For flat taxes the tax function is simply $T_{w}(\hat{y})=\tau_{w} \hat{y}$. With progressive taxes, the wage tax combines a deductible with the requirement that the marginal tax rate is continuous. For progressive taxes the marginal wage tax function is 
$T_{w}^{\prime}(\hat{y})=\max \left\{0, \min \left\{\tau_{\max }, \tau_{1}+\tau_{2} \hat{y}\right\}\right\}$. The top marginal tax rate is set to 0.36 (see the appendix for details).

\section{Simulation Results}

This section presents numerical simulation results that shed light on how redistributive policies affect intergenerational earnings mobility. The experiments compare steady states under alternative policy regimes. The first experiment studies the effects of subsidizing tuition expenditures; the second examines the move from flat to progressive labor income taxation. The main finding in both cases is that the changes in intergenerational mobility are minimal.

\subsection{Tuition Subsidies}

The first experiment is meant to capture the effects of policies that reduce the private costs of education, such as public provision of education, tax exemptions on savings earmarked for educational expenditures, among others. The experiment compares the steady state effects of a $50 \%$ subsidy to tuition payments financed by lump-sum taxation.

Findings. The steady state changes in aggregates are shown in table 5. The tuition subsidy increases college attendance for all but the most able households. As a consequence, college labor input and aggregate output increase and the college wage premium declines. The ability composition of the college population deteriorates, so that the college earnings premium drops. A striking finding is that the tuition subsidy exacerbates earnings inequality: the quintile ratio of lifetime earnings rises by $19.2 \%$. Table 6 shows how the transition matrix for earnings quartiles is modified by the tuition subsidy. The changes are generally minimal, no more than $0.5 \%$ in any cell. Consistent with this finding, the Galton coefficient for earnings is nearly unaffected.

[INSERT TABLE 5 HERE]

[INSERT TABLE 6 HERE]

Table 7 shows transition probabilities for education. The probability of placing a child in college, $\operatorname{Pr}\left(s=2 \mid s^{P}\right)$, increases by $4.6 \%$ for the parents with high school degrees and for $3.9 \%$ for college educated parents. This represents a slight increase in educational mobility. However, the change is so small that the Galton coefficient for education falls by only 0.01 .

The main finding is therefore: Policies that reduce the private cost of education have very little impact on intergenerational mobility. In addition, earnings inequality is not diminished but exacerbated. This finding casts doubt on the common presumption that public education 
finance is an effective tool for achieving "equality of opportunity" for the children of poor parents.

\section{[INSERT TABLE 7 HERE]}

Discussion. The next task is to develop intuition for the two main findings: (i) Earnings inequality increases despite the fact that the policy succeeds in raising college attendance of the children of the poor; (ii) the transition matrix for earnings is nearly unchanged in spite of large changes in school attendance.

First, why does earnings inequality increase? The reason can be seen from table 1: attending college reduces earnings for low ability households. In this sense, the tuition subsidy induces such households to over invest in education. This result may appear surprising or even implausible at first (although HLT obtain a similar finding from a panel of NLSY households). But note that this does not mean that attending college reduces peak earnings. It only means that the increase of peak earnings is not sufficient to compensate the household for losing the first 4 years of working life. Also note that low ability households may still enjoy higher welfare due to the non-pecuniary benefits of attending college. The policy may thus succeed in reducing alternative measures of inequality, even though earnings inequality increases.

To understand the second result, note that individual earnings are largely determined by ability and much less by education (recall table 1). As a consequence, the changes in the transition matrix for abilities mirror those for earnings very closely. The task is therefore to understand why the transition matrix for abilities, $\operatorname{Pr}\left(q \mid q^{P}\right)$, is nearly unaffected by the policy change. Consider the following decomposition:

$$
\operatorname{Pr}\left(q \mid q^{P}\right)=\sum_{s}{ }^{P} \operatorname{Pr}\left(q \mid q^{P}, s^{P}\right) \operatorname{Pr}\left(s^{P} \mid q^{P}\right) .
$$

The interpretation of (6) is that two factors affect the ability distribution of children for a parent with ability $q^{P}$. The first factor is parental schooling choice, $\operatorname{Pr}\left(s^{P} \mid q^{P}\right)$, which affects the parent's human capital endowment at the beginning of work life. The second factor is parental job training, which augments the amount of adult human capital that is transmitted to the child $\left(h^{P}\right)$ and thereby changes $\operatorname{Pr}\left(q \mid q^{P}, s^{P}\right)$.

Note first that job training, and thus $\operatorname{Pr}\left(q \mid q^{P}, s^{P}\right)$, is nearly unaffected by the policy change. Since all inputs to job training are paid for through reduced earnings, changes in wage rates have little direct impact on training investment for households with given $\left(q^{P}, s^{P}\right)$. The changes in $\operatorname{Pr}\left(q \mid q^{P}\right)$ are therefore mostly driven by changes in parental school attendance, $\operatorname{Pr}\left(s^{P} \mid q^{P}\right)$. But these are simply not large enough to generate significant changes in child outcomes. To 
make this statement precise, note that with constant $\operatorname{Pr}\left(q \mid q^{P}, s^{P}\right)$ the changes in transition probabilities are given by

$$
\begin{gathered}
\Delta \operatorname{Pr}\left(q \mid q^{P}\right)=\operatorname{Pr}\left(q \mid q^{P}, s^{P}=2\right) \Delta \operatorname{Pr}\left(s^{P}=2 \mid q^{P}\right)+\operatorname{Pr}\left(q \mid q^{P}, s^{P}=1\right) \Delta \operatorname{Pr}\left(s^{P}=1 \mid q^{P}\right) \\
=\Delta \operatorname{Pr}\left(s^{P}=2 \mid q^{P}\right)\left[\operatorname{Pr}\left(q \mid q^{P}, s^{P}=2\right)-\operatorname{Pr}\left(q \mid q^{P}, s^{P}=1\right)\right]
\end{gathered}
$$

where $\Delta \operatorname{Pr}($.$) denotes the change in a transition probability between the progressive and the flat$ tax steady state. The second equation uses the fact that $\Delta \operatorname{Pr}\left(s^{P}=1 \mid q^{P}\right)=-\Delta \operatorname{Pr}\left(s^{P}=2 \mid q^{P}\right)$. In words: Only parents that alter their education choice contribute to changes in the transition matrix $\operatorname{Pr}\left(q \mid q^{P}\right)$. A parent who switches from high school to college attendance increases the probability that its child has ability $q$ by the term in square brackets.

To see why the changes in (7) are small, it is instructive to work through an example. Consider a median ability parent $\left(q^{P}=2\right)$. For such a parent, the probability of attending college rises substantially, by $\Delta \operatorname{Pr}\left(s^{P}=2 \mid q^{P}\right)=0.063$, but the probability of having a child with $q=4$ rises by only 0.005 . Where does this figure come from? Attending college raises parental human capital $\left(h^{P}\right)$ by 1 (from 1.9 to 2.9 ). The associated increase in the probability of having a highly able child can be approximated by a simple calculation. Human capital of the most able parents exceeds that of the least able parents by about 6. This gap is associated with a difference in $\operatorname{Pr}\left(q=4 \mid q^{P}\right)$ of about 0.33. Taking a linear approximation, increasing $h^{P}$ by 1 raises $\operatorname{Pr}\left(q=4 \mid q^{P}\right)$ by about $0.33 / 6=0.055$. If a parent with $q^{P}=2$ switches from high school to college attainment, the probability of having a child with $q=4$ should therefore rise by approximately

$$
\operatorname{Pr}\left(q=4 \mid q^{P}, s^{P}=2\right)-\operatorname{Pr}\left(q=4 \mid q^{P}, s^{P}=1\right) \approx 0.055
$$

which is not too far from the figure generated by the model $(0.078) .{ }^{6}$ While this is a significant change (it means that the fraction with highly able children rises by more than one third for those who change schooling), it still implies an increase in the fraction of children with high ability of only

$$
\Delta \operatorname{Pr}\left(q=4 \mid q^{P}=2\right) \approx 0.063 \cdot 0.078=0.005
$$

\footnotetext{
${ }^{6}$ It is tempting to argue that $h^{P}$ changes by almost $50 \%$, which should be associated with a larger change in child abilities. However, it is not the percentage change in $h^{P}$ that determines the change in the probability of having a highly able child. What matters is the absolute change in $h^{P}$ relative to the difference in $h^{P}$ between high and low ability parents.
} 
which is very close to the actual value generated by the model (also 0.005). The reason is that only a fraction of ability 2 parents do change their schooling choice and it is the product of the this fraction with the change from (8) that matters for the ability transition matrix.

Similar arguments could be made to establish that the changes in ability persistence are small for parents of other types as well. For parents with lowest ability $\left(q^{P}=1\right)$ the change in school attainment is very large, but education has virtually no effect on $h^{P}$. For high ability parents $h^{P}$ changes by more due to education, but the fraction of parents altering their education choice is small. These calculations suggests that policies which affect only education but not other adult human capital investments (the first term in (6)) are unlikely to have large effects on intergenerational earnings mobility.

To summarize, subsidizing education does achieve its intermediate objective of inducing more low ability households to invest in education. But it fails to accomplish its ultimate objectives: to enhance intergenerational mobility or the earnings of the poor and to reduce lifetime earnings inequality. It is shown next that alternative policies, which raise the relative rewards of human capital investments for the poor, are similarly unsuccessful.

\subsection{Progressive Income Taxation}

This section examines to what extent redistributional tax policies succeed in enhancing intergenerational earnings mobility. The experiment again compares two steady states. The progressive tax steady state is parameterized so as to replicate U.S. data including the progressive income tax system. The flat tax steady state is obtained by replacing the progressive labor income tax by a flat tax. The capital income tax is held constant at $\tau_{K}=0.15$, while the flat wage tax rate $\tau_{w}$ is chosen to maintain government revenues unchanged. Results are reported for the move from the flat rate to the progressive tax system. This addresses the question to what extent existing progressive taxation affects mobility and inequality compared with a hypothetical steady state with flat taxes. ${ }^{7}$

Findings. As in the tuition subsidy experiment, the changes in intergenerational mobility are very small. Table 8 shows that the transition matrix for earnings is nearly unaffected by the tax change, especially for the poor. The main effect of progressive taxation is to reduce the earnings prospects of the children of high ability parents. Overall inequality as measured by the quintile ratio for lifetime earnings falls by $9.4 \%$ (table 5). The persistence of education is

\footnotetext{
${ }^{7}$ This experiment is the reverse of the one studied in HLT who consider the move from a progressive to a flat tax.
} 
virtually unchanged (table 7). As in the previous section, the main finding is that redistributional policies have only a minimal effect on intergenerational mobility.

[INSERT Table 8 HERE]

Discussion. The intuition for this finding is similar to that provided for the tuition subsidy. Recall that the transition matrix for abilities is determined by parental education choice, $\operatorname{Pr}\left(s^{P} \mid\right.$ $\left.q^{P}\right)$, and by the transition matrix $\operatorname{Pr}\left(q \mid q^{P}, s^{P}\right)$. The latter is determined entirely by parental human capital, $h^{P}$. Since job-training inputs are tax-deductible, optimal training investment changes little for most households. The exception are the most able households, for who progressive taxation implies the largest tax increase. Therefore, $h^{P}$ and the distribution of child abilities remain largely unchanged for parents of given types $\left(q^{P}, s^{P}\right)$.

The changes in intergenerational mobility are therefore mostly due to changes in parental schooling decisions. College attendance falls by 0.1 for the most able parents, but rises by around 0.08 for all others (table 5). The reason is that the progressive tax reduces the college premium strongly for highly able households. As these reduce college attendance, the college wage rate $\omega^{2}$ rises. This induces households with lower abilities to increase college attendance. The argument why this does not translate into larger changes of child abilities exactly parallels the tuition subsidy case: given that the tax reform has little impact on job training, significantly altering the transition matrix for abilities (and thus for earnings) would require very large changes in schooling choice.

\subsection{Sensitivity Analysis}

This section examines the robustness of the previous findings. Since intergenerational persistence is not precisely estimated, an important question is how the findings change over the plausible range of persistence measures. Estimates of the Galton coefficient for earnings range from 0.2 to 0.6 (Mulligan 1997, table 7.5). Parameterizing the model to replicate any value in this range has little impact on the predicted changes in earnings persistence and inequality. For the tuition subsidy experiment the Galton coefficient drops by less than $2 \%$ and the quintile rises by at most $21 \%$ in all cases (compared with baseline changes of $0 \%$ and $19.2 \%$ ). For the move to the progressive tax system the maximum changes are $5.3 \%$ and $10.9 \%$. These findings suggest that sensible increases in intergenerational persistence do not overturn the main finding that redistributive policies of the kind studied here have little impact on intergenerational mobility. 
Experimentation with variations of other parameters, such as the substitution elasticity between labor types or the age at which human capital is transmitted from parents to children, did not yield significant changes in any of the results and are therefore not reported.

\section{Conclusion}

This paper examines to what extent redistributive policies succeed in promoting intergenerational earnings mobility. The question is studied in the context of a quantitative lifecycle model with human capital that can account for selected features of U.S. data on intergenerational mobility and lifetime earnings inequality. Two types of policies are considered, both aimed at increasing the returns to human capital accumulation for the children of poor parents. The first type of policy reduces the private cost of education, the second type raises the reward of human capital investments by lowering labor income taxes.

The main finding is that such policies have little impact on intergenerational mobility. Moreover, policies that reduce the private costs of education fail to reduce lifetime earnings inequality. These results are shown to be robust against variations in model parameters, especially the degree of intergenerational persistence. I conclude that public policies of the kind studied here may be largely ineffective in promoting equality of opportunity.

Future research should examine the robustness of these findings to a number of model extensions, such as parental fertility choice (Knowles 1999) or alternative ways of modeling the transfer of human capital. 


\section{References}

Aiyagari, S. Rao; Jeremy Greenwood; Nezih Guner (2000). "On the state of the union." Journal of Political Economy 108.

Becker, Gary S.; Nigel Tomes (1986). "Human Capital and the Rise and Fall of Families." Journal of Labor Economics 4(3): S1-S39.

Behrman, Jere R.; Paul Taubman (1989). "Is Schooling "Mostly in the Genes"? NatureNurture Decomposition Using Data on Relatives." Journal of Political Economy 97(6): 1425-1446

Cameron, S.; J. Heckman (1998). "Lifecycle schooling and educational selectivity: models and choice." Journal of Political Economy 106(2): 262-33.

Castaneda, Ana; Javier Diaz-Giminez; Jose-Victor Rios-Rull (1998). "Earnings and wealth inequality and income taxation: Quantifying the trade-offs of switching the U.S. to a proportional income tax system." Mimeo. University of Pennsylvania.

Cohn, Elchanan; Terry G. Geske (1990). The Economics of Education. Third edition. New York: Pergamon Press.

Ehrlich, Isaac; Francis T. Lui (1990). "Intergenerational Trade, Longevity, and Economic Growth.” Journal of Political Economy 99(5): 1029-59.

Fernandez, Raquel; Richard Rogerson (1997). "Public Education and Income Distribution: A Quantitative Evaluation of Education Finance Reform." Mimeo. University of Minnesota.

Fullerton, Don; Diane L. Rogers (1993). Who Bears the Lifetime Tax Burden? Brookings: Washington, DC.

Haley, William J. (1976). "Estimation of the earnings profile from optimal human capital accumulation." Econometrica 44(6): 1223-38.

Heckman, James J. (1976). “A Life-cycle Model of Earnings, Learning, and Consumption.” Journal of Political Economy 84(4): S11-S44.

Heckman, James; Lance Lochner; Christopher Taber (1998). "Explaining rising wage inequality: Explorations with a dynamic general equilibrium model of labor earnings with heterogeneous agents." Review of Economic Dynamics 1(1): 1-58.

Hendricks, Lutz (1999a). “Taxation and Human Capital Accumulation.” Mimeo. Arizona State University. 
Hendricks, Lutz (1999b). "Taxation and Long-Run Growth." Journal of Monetary Economics (43)2: 411-434.

Hendricks, Lutz (1999c). "How Do Taxes Affect Human Capital? The Role of Intergenerational Mobility." Mimeo. Arizona State University.

Kane, Thomas J. (1994). "College entry by blacks since 1970: the role of college costs, family background, and returns to education." Journal of Political Economy 102(5): 878-911.

Knowles, John (1999). "Social Policy, Equilibrium Poverty and Investment in Children." Mimeo. University of Pennsylvania.

Lucas, Robert E. (1990). "Supply-side Economics: An Analytical Review." Oxford Economic Papers 42 (April): 293-316.

Moffitt, Robert; Peter Gottschalk (1993). "Trends in the covariance structure of earnings in the United States: 1969-87.” Discussion Paper 1001-93. Madison, Wisconsin: Institute for Research on Poverty.

Mulligan, Casey B. (1997). Parental priorities. Chicago: University of Chicago Press.

Murphy, Kevin M.; Finis Welch (1989). "Wage premium for college graduates: recent growth and possible explanations." Educational Researcher 18: 17-26.

Restuccia, Diego; Carlos Urrutia (1999). "Intergenerational Income Persistence: Sources and Policy." Mimeo. University of Toronto. 


\section{Tables}

Table 1. Distribution of lifetime earnings

\begin{tabular}{lrrrr}
\hline \hline & & & & \\
& $q=1$ & $q=2$ & $q=3$ & \\
\hline $\begin{array}{l}\text { Present value of } \\
\text { earnings }\left(E_{q, s}\right)\end{array}$ & & & & \\
$\quad s=1$ & 234,752 & 421,667 & 582,668 & 778,706 \\
$\quad s=2$ & 149,501 & 411,993 & 601,300 & 903,702 \\
$\begin{array}{l}\text { College premium } \\
\text { Fraction with } \\
\text { college }\end{array}$ & -36.3 & -2.3 & 3.2 & 16.1 \\
& 9.4 & 15.4 & 23.4 & 41.7 \\
\hline \hline
\end{tabular}

Notes: The present value of earnings is measured in 1992 dollars. The college premium is defined as (average earnings of all college graduates) / (average earnings of all others).

Table 2. Probability that a child attends college

\begin{tabular}{lrrrr}
\hline \hline & & & & \\
& $q=1$ & $q=2$ & $q=3$ & $q=4$ \\
$s^{P}=1$ & 6.6 & 11.0 & 15.8 & 25.2 \\
$s^{P}=2$ & 24.8 & 54.7 & 52.6 & 68.9 \\
\hline \hline
\end{tabular}

Notes: The table shows $100 \cdot \operatorname{Pr}\left(s=2 \mid q, s^{P}\right)$.

Table 3. Transition probabilities for child ability

\begin{tabular}{cccccr}
\hline \hline & & & & & \\
\hline$q^{P}=1$ & $s^{P}=1$ & 45.5 & 28.0 & 17.9 & 8.6 \\
& $s^{P}=2$ & 26.5 & 27.9 & 25.7 & 19.9 \\
$q^{P}=4$ & $s^{P}=1$ & 17.5 & 24.6 & 28.2 & 29.6 \\
& $s^{P}=2$ & 10.4 & 19.5 & 28.1 & 41.9 \\
\hline \hline
\end{tabular}

Notes: The table shows $100 \cdot \operatorname{Pr}\left(q \mid q^{P}, s^{P}\right)$. 


\begin{tabular}{|c|c|c|c|}
\hline \multicolumn{2}{|c|}{ Households } & \multicolumn{2}{|c|}{ Education } \\
\hline$a_{R}=64$ & $\begin{array}{l}\text { Labor force } \\
\text { participation data }\end{array}$ & $\begin{array}{r}a_{0}=7 \\
a_{s}=[18,22]\end{array}$ & School enrollment data \\
\hline$a_{c}=16$ & Start of consumption & $H_{q, s}$ & Matches estimated $E_{q, s}$ \\
\hline$a_{B}=30$ & Age of child birth & $\mu(q), v(s)$ & Matches $\operatorname{Pr}(s \mid q)$ \\
\hline $\begin{aligned} a_{L} & =75 \\
\sigma & =2\end{aligned}$ & Age of death & $\sigma(q)$ & $\begin{array}{l}\text { Matches sensitivity of } \\
\text { college enrollment to } \\
\text { tuition changes }\end{array}$ \\
\hline $\begin{array}{r}\beta \\
Q_{q} \\
\alpha\left(s^{P}\right)\end{array}$ & $\begin{array}{l}\text { Matches } K / Y=2.5 \\
\text { Matches } \operatorname{Pr}(q) \\
\text { Matches } \\
\operatorname{Pr}\left(q>2 \mid q^{P}>2, s^{P}\right)\end{array}$ & & $\begin{array}{l}\text { Matches aggregate } \\
\text { tuition spending of } \\
0.7 \% \text { of } Y\end{array}$ \\
\hline & Firms & \multicolumn{2}{|c|}{ Job Training } \\
\hline$\theta=0.3$ & Capital share in GNP & \multirow[t]{2}{*}{$B_{s}$} & Matches earnings \\
\hline$\delta_{K}=0.08$ & Matches $I / Y=0.2$ & & $\begin{array}{l}\text { growth between ages } \\
25 \text { and } 48\end{array}$ \\
\hline \multirow{2}{*}{$1 /(1-\rho)=1.441$} & $\begin{array}{l}\text { Matches ratio of college } \\
\text { to high school earnings }\end{array}$ & $\begin{array}{r}\varphi=0.45 \\
\psi=0.3\end{array}$ & $\begin{array}{l}\text { Heckman (1976), Haley } \\
\text { (1976) }\end{array}$ \\
\hline & HLT & $\delta_{h}=0$ & HLT \\
\hline
\end{tabular}


Table 5. Changes in aggregates

\begin{tabular}{lrr}
\hline \hline & & \\
& $\begin{array}{r}\text { Education } \\
\text { subsidy }\end{array}$ & $\begin{array}{r}\text { Move to progressive } \\
\text { wage taxation }\end{array}$ \\
\hline Output & -0.8 & -1.6 \\
Capital stock & -0.5 & 1.0 \\
Labor input & -1.0 & -2.7 \\
High school labor input $\left(L^{1}\right)$ & -3.2 & -0.7 \\
College labor input $\left(L^{2}\right)$ & 3.8 & -6.9 \\
High school wage rate $\left(\omega^{1}\right)$ & 1.7 & -0.3 \\
College wage rate $\left(\omega^{2}\right)$ & -3.1 & 4.3 \\
& & 3.1 \\
Fraction with college degree & 7.8 & 6.2 \\
$\quad q=1$ & 27.6 & 9.3 \\
$\quad q=2$ & 6.3 & 8.0 \\
$\quad q=3$ & 1.5 & -10.8 \\
$\quad q=4$ & -4.3 & -18.0 \\
Fraction among college educated & & -9.3 \\
with $q=1$ & 19.9 & -0.0 \\
with $q=4$ & -15.3 & 0.00 \\
College premium & & \\
Gaintile ratio & 0.1 & \\
\hline \hline
\end{tabular}

Notes: Changes of fractions in percentage points. Other changes in percent. 
Table 6 . Changes in transition probabilities for earnings quartiles; $50 \%$ tuition subsidy

\begin{tabular}{lcccc}
\hline $\begin{array}{c}\text { Child's } \\
\text { quartile }\end{array}$ & 1 & 2 & 3 & 4 \\
\hline 1 & 0.0 & -0.1 & -0.2 & 0.3 \\
2 & -0.5 & -0.2 & 0.3 & 0.4 \\
3 & -0.1 & 0.1 & 0.1 & -0.1 \\
4 & 0.0 & 0.2 & 0.1 & -0.4 \\
\hline
\end{tabular}

Notes: The table shows steady state changes. The figures are percentage changes.

Table 7. Transition probabilities for education

\begin{tabular}{lcccrr}
\hline \hline & \multicolumn{2}{c}{ Levels } & & \multicolumn{2}{c}{ Changes [\%] } \\
\cline { 2 - 5 } & Data & Baseline & & $\begin{array}{r}\text { Education } \\
\text { subsidy }\end{array}$ & $\begin{array}{r}\text { Move to } \\
\text { progressive tax }\end{array}$ \\
\cline { 2 - 6 } $\operatorname{Pr}\left(s=2 \mid s^{P}=1\right)$ & 13.7 & 12.7 & & 4.6 & 1.7 \\
$\operatorname{Pr}\left(s=2 \mid s^{P}=2\right)$ & 57.2 & 56.2 & 3.9 & 2.0 \\
\hline \hline
\end{tabular}


Table 8. Changes in transition probabilities for earnings quintiles. Move to progressive taxes.

\begin{tabular}{lcccc}
\hline & $\begin{array}{c}\text { Child's } \\
\text { quintile }\end{array}$ & 1 & 2 & \\
$\begin{array}{l}\text { Parent's } \\
\text { quintile }\end{array}$ & 0.0 & 0.1 & 0.2 & -0.3 \\
\hline 1 & -1.0 & -0.3 & 0.2 & 1.2 \\
2 & -0.6 & -0.4 & 0.1 & 0.9 \\
3 & 1.2 & 1.2 & 0.4 & -2.8 \\
\hline \hline
\end{tabular}

Notes: The table shows steady state changes due to moving to progressive wage taxation. The figures are percentage changes. 


\section{Appendix: Parameter Choices}

Households. The standard deviation of $p_{\mathrm{s}}$ is chosen to match Kane's (1994) estimates of the responsiveness of college enrollment to tuition changes. He finds that a $\$ 1,000$ increase in tuition reduces enrollment by $4.6 \%$ for the lowest family income class, but by only $1.2 \%$ for the highest. The average change across all households is $3.2 \%$. The $\sigma(q)$ are chosen to replicate the $4.6 \%$ figure for the lowest ability class and an average response of $3.2 \%$. Translating $\$ 1000$ into model units requires to express it as a fraction of average per capita earnings. In 1990 median weekly earnings of one-earner households are $\$ 455$, so that $\$ 1000$ represent approximately 4\% of annual median earnings (Statistical Abstract of the United States 1993, table 672).

Tuition. The tuition variable represents the annual direct cost of attending college. This should include all privately paid costs, except forgone earnings. There is no tuition for high school, reflecting the fact that $90 \%$ of the direct cost of high school education is paid for by the public sector (Cohn and Geske 1990). In 1990, tuition and fees for colleges and other higher education amounted to $\$ 37.4$ billion or $0.67 \%$ of GDP. Since the model understates the size of the college population (all who enroll finish within four years) and since the tuition subsidy should only affect the part of education costs that represents tuition payments, the ratio of aggregate college tuition to output is set to $0.5 \%$.

Government. The wage tax function for the progressive case is given by

$$
T_{w}(\hat{y})=\left\{\begin{array}{ccc}
\mathrm{T}_{0} & \text { if } & \hat{y}<y_{0} \\
\tau_{1} \hat{y}+0.5 \tau_{2} \hat{y}^{2} & \text { if } & y_{0} \leq \hat{y} \leq y_{1} \\
\mathrm{~T}_{3}+\tau_{\max } \hat{y} & \text { if } & \hat{y}>y_{1}
\end{array}\right.
$$

The marginal labor tax schedule is piecewise linear in earnings:

$$
T_{w}^{\prime}(\hat{y})=\left\{\begin{array}{ccc}
0 & \text { if } & \hat{y}<y_{0} \\
\tau_{1}+\tau_{2} \hat{y} & \text { if } & y_{0} \leq \hat{y} \leq y_{1} \\
\tau_{\max } & \text { if } & \hat{y}>y_{1}
\end{array}\right.
$$

Given the choice of range boundaries below, this simplifies to

$$
T_{w}^{\prime}(\hat{y})=\max \left\{0, \min \left\{\tau_{\max }, \tau_{1}+\tau_{2} \hat{y}\right\}\right\}
$$

The range boundaries are defined such that the average tax schedule is continuous: $\tau_{1} y_{0}+0.5 \tau_{2} y_{0}^{2}=\mathrm{T}_{0}$ and $\mathrm{T}_{3}+\tau_{\max } y_{1}=\tau_{1} y_{1}+0.5 \tau_{2} y_{1}^{2}$. The slope coefficients are defined so that the marginal tax schedule is continuous: $\tau_{1}+\tau_{2} y_{0}=0$ and $\tau_{1}+\tau_{2} y_{1}=\tau_{\max }$. In 
addition, I require a marginal tax rate at zero net earnings of $\tau_{1}$. The income level at which maximum taxes are reached is specified exogenously $\left(y_{1}\right)$.

Based on Internal Revenue Service data for 1998, $\tau_{1}$ and $\tau_{2}$ are chosen to match marginal tax rates of 0.15 at $y=y^{*}$ and the maximum marginal tax rate of $\tau_{\max }=0.36$ at $y_{1}=\$ 70,000$. This neglects the fact that in the U.S. tax code an additional tax bracket exists. It has a marginal tax rate of $39.6 \%$ for AGI's over $\$ 278,000$. The model does not have households with earnings that high. The deductible is $y^{*}=\$ 9,660$ (see HLT). Average earnings per adult are set to $\$ 30,000$. 